\title{
Estrutura de um fragmento de Floresta Atlântica em regeneração com ocorrência de Caesalpinia echinata Lam. (pau-brasil)
}

\author{
Liliane Baldan Zani * \\ Valderes Bento Sarnaglia Junior \\ José Manoel Lúcio Gomes \\ Luciana Dias Thomaz \\ Universidade Federal do Espírito Santo \\ Departamento de Ciências Biológicas, Setor Botânica \\ Av. Fernando Ferrari, 514, CEP 29075-910, Vitória - ES, Brasil \\ * Autor para correspondência \\ lilianebaldan@yahoo.com.br
}

Submetido em 04/11/2011

Aceito para publicação em 24/08/2012

\section{Resumo}

Este trabalho teve por objetivo analisar a estrutura fitossociológica de um fragmento remanescente de Floresta Atlântica em regeneração no município de Aracruz-ES em uma floresta de tabuleiro com ocorrência natural de Caesalpinia echinata Lam. Foram instaladas 10 unidades amostrais (parcelas) de 10 x 50m sendo amostrados todos os indivíduos com DAP $\geq 5 \mathrm{~cm}$ e $<10 \mathrm{~cm}$. Ao todo foram amostrados 500 indivíduos distribuídos em 181 espécies. As famílias com maior riqueza foram Leguminosae (35), Sapotaceae (18) e Myrtaceae (14). As espécies mais importantes foram Caesalpinia echinata Lam., Eugenia tinguyensis Cambess. e Pterocarpus rohrii Vahl. O índice de Shannon (H') foi de 4,89 e a equabilidade (J') foi de 0,94. Essa área é um dos últimos fragmentos remanescentes com pau-brasil nativo do estado do Espírito Santo e a população dessa espécie encontra-se bem preservada no local, ocorrendo com grande frequência, enfatizando a importância da preservação de pequenos fragmentos florestais para conservação da biodiversidade.

Palavras-chave: Espírito Santo; Fitossociologia; Floresta de tabuleiro; Pau-brasil

\section{Abstract}

Structure of a fragment of Atlantic Rainforest in regeneration with occurrence of Caesalpinia echinata Lam. (brazil-wood). This study aimed to evaluate the phytosociological structure of a remaining fragment of Atlantic Rainforest undergoing regeneration in the town of Aracruz-ES in a forest board with natural occurrence of Caesalpinia echinata Lam. We installed 10 sample units (plots) of 10 x 50m, sampling all individuals with $\mathrm{DBH} \geq 5 \mathrm{~cm}$ and $<10 \mathrm{~cm}$. Altogether, we sampled 500 individuals distributed into 181 species. The richest families were Leguminosae (35), Sapotaceae (18), and Myrtaceae (14). The most important species were Caesalpinia echinata Lam., Eugenia tinguyensis Cambess., and Pterocarpus rohrii Vahl. The Shannon index (H') was 4.89 and the equability $\left(\mathrm{J}^{\prime}\right)$ was 0.94 . This area is one of the last remaining fragments with brazil-wood from the state of Espirito Santo and the population of this species is well preserved at the site, it occurs very frequently, emphasizing the importance of preserving small forest fragments to conserve biodiversity.

Key words: Brazil-wood; Espirito Santo; Forest board; Phytosociology 


\section{Introdução}

No Espírito Santo a Floresta Atlântica ocupava os 4.614.841ha de sua área territorial, porém o diagnóstico atual da cobertura vegetal neste estado revela que, da cobertura original dessa floresta, há somente $11,07 \%$ de cobertura remanescente, ou seja, 510.752ha (SOS MATA ATLÂNTICA; INPE, 2011). Esses remanescentes de Floresta Atlântica encontram-se intensamente fragmentados, o que é muito preocupante, porque, segundo Tabarelli et al. (1999) a fragmentação de habitats é uma das principais causas de perda da biodiversidade em florestas tropicais.

Um exemplo são as Florestas de Tabuleiros da região norte do Espírito Santo que estão altamente fragmentadas e atualmente protegidas por poucas unidades de conservação existentes na região. Embora se tenha a maior parte dos trabalhos de tabuleiros realizados nestas áreas, muito ainda se tem a estudar nelas, principalmente nas que não são protegidas por unidades de conservação e que ainda abrigam espécies endêmicas como o pau-brasil.

O pau-brasil, Caesalpinia echinata Lam. (Leguminosae - Caesalpinioideae), é uma espécie arbórea endêmica brasileira típica da Floresta Atlântica, sua ocorrência natural vai do estado do Rio Grande do Norte ao Rio de Janeiro (CARVALHO, 1994). A exploração descontrolada dessa espécie é um dos clássicos exemplos de distúrbio causado à Mata Atlântica, iniciado logo após a ocupação da costa brasileira pelos colonizadores portugueses, reduzindo sua distribuição original a pequenos remanescentes na atualidade (CARDOSO et al.,1998). Durante muitos anos acreditou-se que ela estivesse extinta no Espírito Santo, sendo que no ano de 2008 populações de paubrasil foram encontradas em fragmentos florestais no município de Aracruz, na Mesorregião Litoral Norte do Espírito Santo.

Segundo Rocha e Simabukuro (2008), a ausência de Unidades de Conservação no Espírito Santo com populações significativas de pau-brasil é um entrave à conservação in situ, pois caracteriza uma descontinuidade de sua distribuição geográfica original. Mas a ocorrência de pelo menos uma área apresenta valor para a conservação, já que carrega um potencial genético característico (PRIMACK; RODRIGUES, 2001). A luta pela preservação de espécies ameaçadas de extinção representa uma valiosa estratégia para a conservação ambiental elegendo "espécies bandeira" que são utilizados em prol da proteção de importantes ambientes naturais, sendo o pau-brasil uma espécie com um grande potencial para essa luta (LINO; BECHARA, 2002).

Com base nisto, o objetivo desse trabalho foi caracterizar a estrutura fitossociológica de um fragmento de Floresta Atlântica em regeneração onde ocorrem populações naturais de Caesalpinia echinata, visando subsidiar informações de conhecimento florístico, fitossociológico e do estado de conservação da área.

\section{Material e Métodos}

\section{Área de estudo}

O fragmento florestal onde foi realizado o estudo está situado no município de Aracruz, distrito de Barra Riacho, na mesorregião Litoral Norte do Espírito Santo, nas coordenadas $19^{\circ} 40^{\prime} 30^{\prime} \mathrm{S}$ e $40^{\circ} 09^{\prime} 10^{\prime} \mathrm{W}$. A área é identificada como AI do Limão (área de identificação utilizada pela proprietária da área de estudo - Fibria.) (Figura 1).

O fragmento analisado possui aproximadamente 30 ha com altitude variando entre $30 \mathrm{~m}$ e $45 \mathrm{~m}$. A área do Limão já teve, na sua porção anterior, uma grande área destinada ao plantio de limão, mas hoje essa plantação deu lugar a um pasto.

De acordo com a classificação de Köppen (KÖPPEN; GEIGER, 1928) o clima da região é tropical úmido (Aw), com estação chuvosa no verão e seca no inverno e a temperatura média anual das estações é de $23^{\circ} \mathrm{C}$ (EMBRAPA, 2000). Nos anos de 1999 a 2009, a precipitação média anual na estação meteorológica de Jacupemba (Aracruz/ES) foi de $1332 \mathrm{~mm}$, sendo que os meses de primavera e verão representam $75 \%$ da precipitação total anual e nos meses de julho e agosto as precipitações mensais são menores que $41 \mathrm{~mm}$ (ANA, 2010) (Figura 2). 
FIGURA 1: Localização do município de Aracruz e AI do Limão, Aracruz/ES.

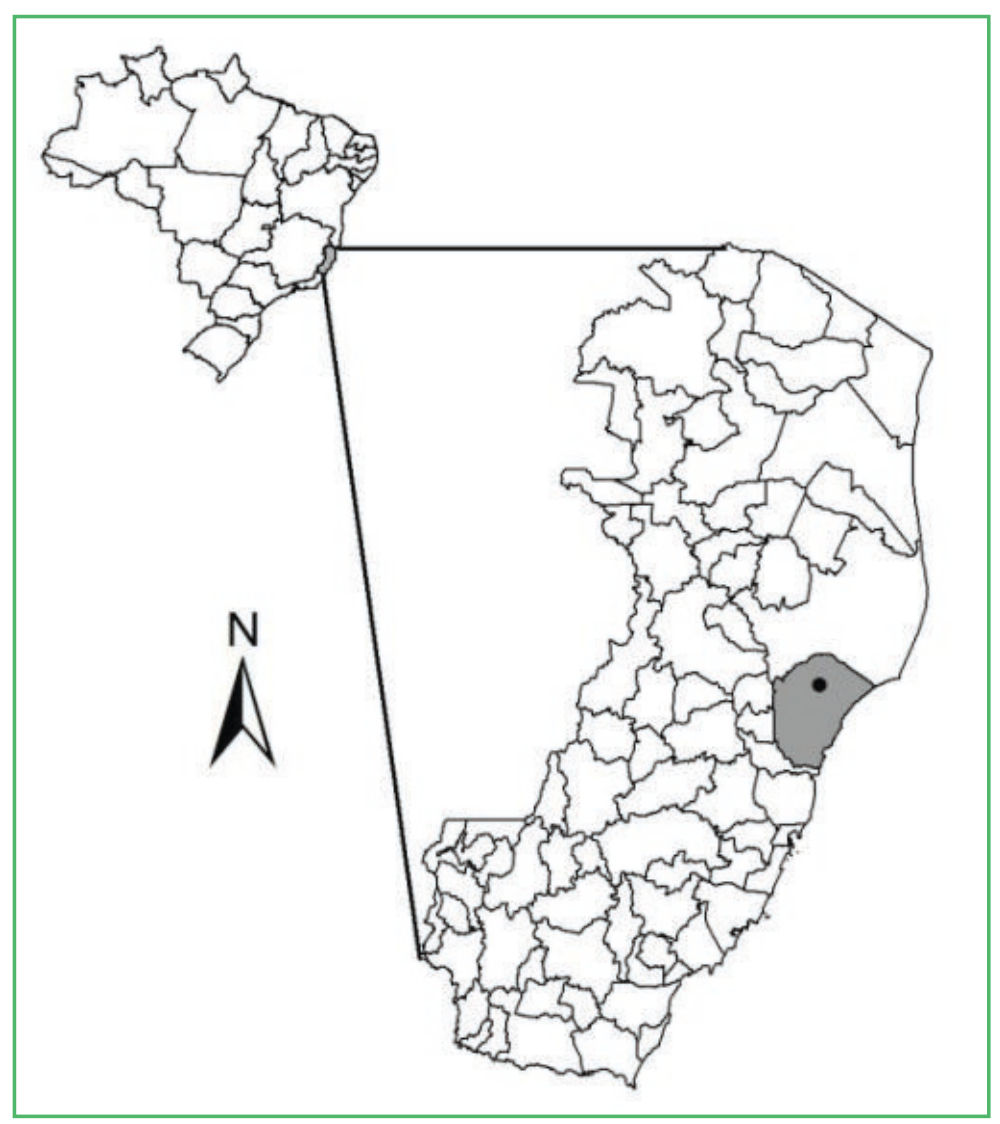

FIGURA 2: Precipitação pluviométrica média mensal (mm) entre 1999-2009 (10 anos), estação pluviométrica de Jacupemba (Aracruz/ ES), ANA (2010).

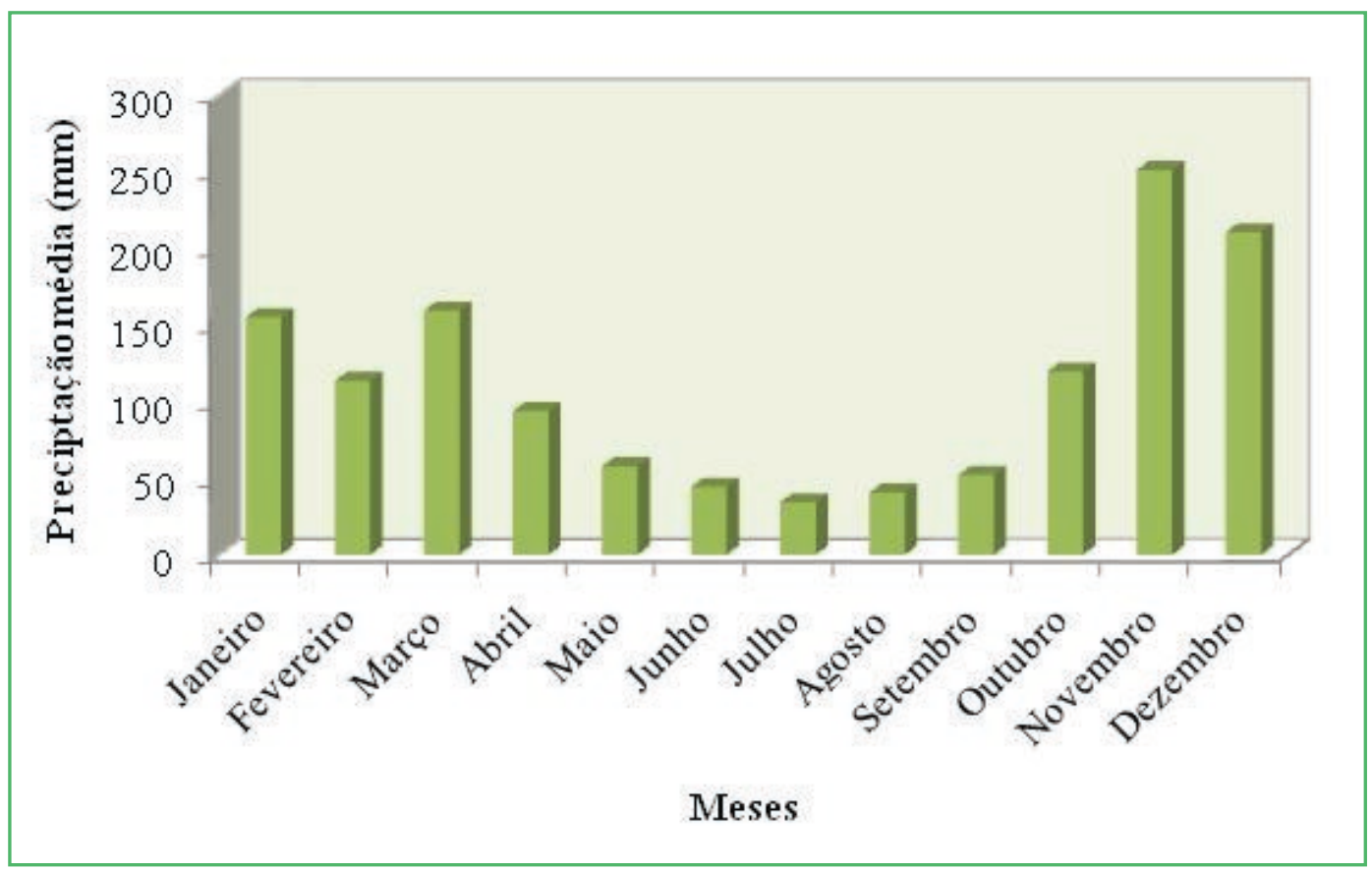


O fragmento estudado encontra-se sobre terrenos terciários formados por depósitos de sedimentos do Grupo Barreiras que são de origem fluvial e sua fonte é atribuída ao desmonte de grandes áreas continentais soerguidas. A sedimentação ocorreu no Terciário, prolongando-se até o Quaternário (PETRI; FÚLFARO, 1983). No estado do Espírito Santo, os sedimentos do Terciário formam os tabuleiros costeiros, distribuídos ao longo do litoral (AMADOR, 1982).

A vegetação do fragmento pode ser classificada, utilizando-se o Projeto RADAMBRASIL (BRASIL, 1987), como Floresta Ombrófila Densa das Terras Baixas, mas também é conhecida como Florestas de Tabuleiros. As Florestas de Tabuleiros são caracterizadas por uma vegetação com exemplares de altura média acima de 30m, as árvores são espaçadas, o sub-bosque é pouco denso e com poucas epífitas (IBGE, 2004).

\section{Amostragem fitossociológica}

Foram instaladas dez unidades amostrais (parcelas) de $10 \times 50 \mathrm{~m}$, dispostas sistematicamente a partir de $50 \mathrm{~m}$ da borda da mata, no sentido da trilha principal e equidistantes $100 \mathrm{~m}$ entre si, totalizando uma área amostral de 0,5ha.

Em cada unidade amostral, todos os indivíduos que possuíam diâmetro à altura do peito (DAP) na faixa de $05 \mathrm{~cm}$ a $10 \mathrm{~cm}$ foram marcados com placas de alumínio a 1,40m acima do nível do solo. Indivíduos perfilhados, incluídos no critério acima, também foram medidos e árvores mortas não entraram na amostragem.

Durante a amostragem foi coletado material fértil e/ou vegetativo para identificação, sendo a herborização de acordo com técnicas usuais (FIDALGO; BONONI, 1984). O material fértil foi depositado na coleção do Herbário Central da Universidade Federal do Espírito Santo, Vitória-ES (VIES), e o material vegetativo serviu como coleção de referência do projeto. A classificação das famílias botânicas foi feita de acordo com APG III (2009).

\section{Análise de dados}

A análise dos dados fitossociológicos foi baseada em Mueller-Dombois e Ellenberg (1974) através do programa Matanativa (CIENTEC, 2006) considerando a Frequência Absoluta $(\mathrm{FAi}=(\mathrm{Pi} / \mathrm{P})$. 100), Frequência Relativa $\left[\mathrm{FR}=\left(\mathrm{FAi} / \sum \mathrm{FA}\right) .100\right]$, Densidade Absoluta $(\mathrm{DA}=$ ni/A), Densidade Relativa $[\mathrm{DR}=(\mathrm{ni} / \mathrm{N}) .100]$, Dominância Absoluta (DoA $=\mathrm{ABi} / \mathrm{A})$, Dominância Relativa (DoR $=\mathrm{ABi} / \mathrm{AB})$, Valor de Importância (VI $=\mathrm{DR}+\mathrm{FR}+\mathrm{DoR})$, Valor de Cobertura (DR + DoR).

Para o cálculo da diversidade de espécies foi utilizado o índice de Shannon (H') (PIELOU, 1975) e para o cálculo da similaridade de unidades amostrais foi utilizado o método de Jaccard (BROWER; ZAR, 1977), usando o software PAST (HAMMER et al., 2001), o cladograma foi construído através do UPGMA (MICHENER; SOKAL, 1957).

Foram utilizadas as listas da IUCN (2009), a Lista Oficial das Espécies da Flora Brasileira Ameaçadas de Extinção (MMA, 2008), a Lista de Espécies Ameaçadas de Extinção no Espírito Santo (ESPÍRITO SANTO, 2005), para averiguar o status de vulnerabilidade de cada espécie e a Lista de plantas raras do Brasil (GIULIETTI et al., 2009).

\section{Resultados}

\section{Estrutura da floresta}

O número de indivíduos amostrados por unidade amostral variou de 33 a 69 totalizando 500 indivíduos e a área basal de 2,4 a $5,0 \mathrm{~m}^{2} \cdot \mathrm{ha}^{-1}$ sendo a média de $4,0 \mathrm{~m}^{2} \cdot \mathrm{ha}^{-1}$. A maior densidade de indivíduos ocorreu na classe de 5,0 a 6,0 cm de DAP. As espécies com maior VI foram Caesalpinia echinata, Eugenia tinguyensis e Pterocarpus rohrii, e a maior densidade de indivíduos ocorreu nas classes de menor diâmetro (Figura 3).

\section{Aspectos florísticos efitossociológicos}

Os 500 indivíduos vivos amostrados foram distribuídos em 41 famílias, sendo as famílias Leguminosae (35), Sapotaceae (18), Myrtaceae (14), Euphorbiaceae (10) e Rubiaceae (9) as que apresentaram a maior riqueza de espécies e correspondem juntas a quase metade do total de espécies amostradas na área $(46,7 \%)$ (Tabela 1). 
FIGURA 3: Distribuição diamétrica de todos os indivíduos e para as três espécies de maior VI amostradas na AI do Limão, Aracruz, ES. A) Todos os indivíduos amostrados ( $\mathrm{n}=500)$; B) Caesalpinia echinata $(\mathrm{n}=17)$; C) Eugenia tinguyensis $(\mathrm{n}=12)$; D) Pterocarpus rohrii $(\mathrm{n}=12)$.

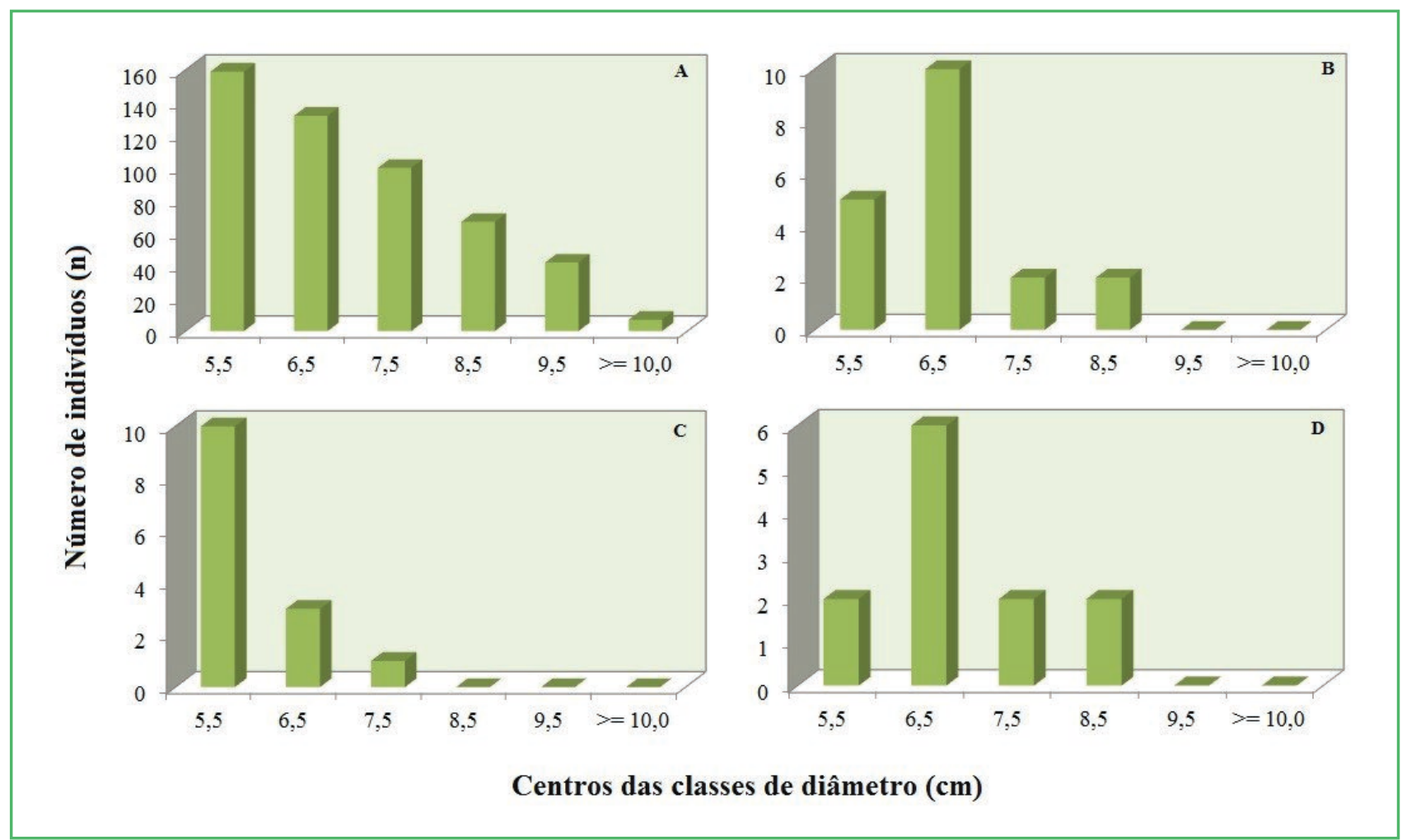

TABELA 1: Famílias com maior riqueza de espécies em um remanescente de Floresta Tropical com Caesalpinia echinata. Aracruz/ES.

\begin{tabular}{|l|c|l|c|}
\hline Família & $\begin{array}{c}\text { № de } \\
\text { espécies }\end{array}$ & Família & $\begin{array}{c}\text { № de } \\
\text { espécies }\end{array}$ \\
\hline Leguminosae & 35 & Sapindaceae & 08 \\
Sapatoceae & 18 & Moraceae & 07 \\
Myrtaceae & 14 & Lauraceae & 06 \\
Euphorbiaceae & 10 & Chrysobalanaceae & 06 \\
Rubiaceae & 09 & Salicaceae & 05 \\
Outras 31 famílias & & & 63 \\
\hline Total & & & 181 \\
\hline
\end{tabular}

Os 500 indivíduos pertencem a 181 espécies, sendo que um total de 145 foi identificado em nível de espécie, 27 apenas em nível de gênero e nove só em nível de família (Tabela 2). Nenhuma espécie ocorreu em todas as unidades amostrais, sendo que Eugenia tinguyensis foi a que apresentou maior frequência, ocorrendo em nove das 10 unidades amostrais, seguida de Caesalpinia echinata que ocorreu em sete unidades amostrais e Eriotheca macrophylla, Guapira opposita, Lecythis lurida, Pterocarpus rohrii e Sorocea guilleminiana que foram amostradas em seis unidades amostrais cada, o restante das espécies ocorreu em cinco ou menos unidades amostrais. Das espécies amostradas, 76 ocorreram com apenas um indivíduo, correspondendo a $41,3 \%$ do total. Em relação ao valor de importância nenhuma espécie destacou-se muito sobre as outras, e as espécies que apresentaram os maiores valores foram Caesalpinia echinata, Eugenia tinguyensis e Pterocarpus rohrii, que juntas somam pouco mais de 7\% do VI (Tabela 2). 
TABELA 2: Parâmetros fitossociológicos de todas as espécies em ordem decrescente de VI amostrados na AI do Limão, Aracruz/ES. Sendo: número de indivíduos (N), área basal (AB), densidade relativa (DR), frequência relativa (FR), dominância relativa (DoR), índice de valor de cobertura (VC), índice de valor de importância (VI). A família Leguminosae está representada em subfamílias (POLHILL; RAVEN, 1981).

\begin{tabular}{|c|c|c|c|c|c|c|c|c|c|c|}
\hline Nome Científico & Família & $\mathbf{N}$ & $\mathbf{A B}$ & DR & FR & DoR & VC & VC (\%) & VI & VI $(\%)$ \\
\hline Caesalpinia echinata Lam. & Caesalpinioideae & 19 & 0,0633 & 3,74 & 1,94 & 3,12 & 6,863 & 3,43 & 8,802 & 2,93 \\
\hline Eugenia tinguyensis Cambess. & Myrtaceae & 12 & 0,0342 & 2,36 & 2,49 & 1,69 & 4,052 & 2,03 & 6,545 & 2,18 \\
\hline Pterocarpus rohrii Vahl & Papilionoideae & 12 & 0,0449 & 2,36 & 1,66 & 2,22 & 4,578 & 2,29 & 6,240 & 2,08 \\
\hline Lecythis lurida (Miers) S.A. Mori & Lecythidaceae & 10 & 0,0454 & 1,97 & 1,66 & 2,24 & 4,210 & 2,11 & 5,872 & 1,96 \\
\hline Sorocea guilleminiana Gaudich. & Moraceae & 10 & 0,0451 & 1,97 & 1,66 & 2,23 & 4,197 & 2,10 & 5,859 & 1,95 \\
\hline Eugenia platyphylla O. Berg & Myrtaceae & 12 & 0,0422 & 2,36 & 1,39 & 2,08 & 4,444 & 2,22 & 5,83 & 1,94 \\
\hline Rinorea bahiensis (Moric.) Kuntze & Violaceae & 09 & 0,0487 & 1,77 & 1,39 & 2,4 & 4,176 & 2,09 & 5,561 & 1,85 \\
\hline Inga flagelliformis (Vell.) Mart. & Mimosoideae & 10 & 0,0410 & 1,97 & 1,39 & 2,03 & 3,994 & 2,00 & 5,379 & 1,79 \\
\hline Machaerium fulvovenosum Lima & Papilionoideae & 07 & 0,0585 & 1,38 & 0,83 & 2,89 & 4,263 & 2,13 & 5,095 & 1,70 \\
\hline Moldenhawera papillanthera L.P. Queiroz et al. & Caesalpinioideae & 08 & 0,0394 & 1,57 & 1,39 & 1,95 & 3,522 & 1,76 & 4,907 & 1,64 \\
\hline Guapira opposita (Vell.) Reitz & Nyctaginaceae & 07 & 0,0341 & 1,38 & 1,66 & 1,68 & 3,062 & 1,53 & 4,724 & 1,57 \\
\hline Astrocaryum aculeatissimum (Schott) Burret & Arecaceae & 06 & 0,0467 & 1,18 & 1,11 & 2,31 & 3,486 & 1,74 & 4,594 & 1,53 \\
\hline Carpotroche brasiliensis (Raddi) A. Gray & Achariaceae & 07 & 0,0362 & 1,38 & 1,39 & 1,79 & 3,166 & 1,58 & 4,552 & 1,52 \\
\hline Actinostemon estrellensis (Müll. Arg.) Pax & Euphorbiaceae & 08 & 0,0275 & 1,57 & 1,39 & 1,36 & 2,93 & 1,47 & 4,315 & 1,44 \\
\hline Melanoxylon brauna Schott & Caesalpinioideae & 07 & 0,0372 & 1,38 & 1,11 & 1,83 & 3,212 & 1,61 & 4,32 & 1,44 \\
\hline Eriotheca macrophylla (K. Schum.) A. Robyns & Malvaceae & 06 & 0,0193 & 1,18 & 1,66 & 0,95 & 2,135 & 1,07 & 3,797 & 1,27 \\
\hline Virola gardneri (A. DC.) Warb. & Myristicaceae & 06 & 0,0300 & 1,18 & 1,11 & 1,48 & 2,662 & 1,33 & 3,770 & 1,26 \\
\hline Senefeldera multiflora Mart. & Euphorbiaceae & 08 & 0,0250 & 1,57 & 0,83 & 1,23 & 2,809 & 1,40 & 3,640 & 1,21 \\
\hline Ocotea sp. 1 & Lauraceae & 06 & 0,0243 & 1,18 & 1,11 & 1,2 & 2,380 & 1,19 & 3,488 & 1,16 \\
\hline Cupania rugosa Radlk. & Sapindaceae & 06 & 0,0179 & 1,18 & 1,11 & 0,89 & 2,067 & 1,03 & 3,175 & 1,06 \\
\hline Cunuria sp. & Euphorbiaceae & 05 & 0,0203 & 0,98 & 1,11 & 1,00 & 1,985 & 0,99 & 3,093 & 1,03 \\
\hline Pseudobombax grandiflorum (Cav.) A. Robyns & Malvaceae & 04 & 0,0277 & 0,79 & 0,83 & 1,37 & 2,154 & 1,08 & 2,986 & 1,00 \\
\hline Toulicia patentinervis Radlk. & Sapindaceae & 06 & 0,0193 & 1,18 & 0,83 & 0,95 & 2,136 & 1,07 & 2,967 & 0,99 \\
\hline Thyrsodium schomburgkianum Benth. & Anacardiaceae & 04 & 0,0154 & 0,79 & 1,11 & 0,76 & 1,546 & 0,77 & 2,654 & 0,88 \\
\hline Coutarea hexandra (Jacq.) K. Schum. & Rubiaceae & 04 & 0,0197 & 0,79 & 0,83 & 0,97 & 1,758 & 0,88 & 2,589 & 0,86 \\
\hline Ocotea confertiflora (Meisn.) Mez & Lauraceae & 05 & 0,0156 & 0,98 & 0,83 & 0,77 & 1,753 & 0,88 & 2,584 & 0,86 \\
\hline Annona dolabripetala Raddi & Annonaceae & 05 & 0,0204 & 0,98 & 0,55 & 1,00 & 1,989 & 0,99 & 2,543 & 0,85 \\
\hline Cupania scrobiculata Rich. & Sapindaceae & 04 & 0,0136 & 0,79 & 1,11 & 0,67 & 1,457 & 0,73 & 2,565 & 0,85 \\
\hline Sclerolobium striatum Dwyer & Caesalpinioideae & 05 & 0,0152 & 0,98 & 0,83 & 0,75 & 1,733 & 0,87 & 2,564 & 0,85 \\
\hline Tabebuia obtusifolia (Cham.) Bureau & Bignoniaceae & 04 & 0,0123 & 0,79 & 1,11 & 0,61 & 1,393 & 0,70 & 2,501 & 0,83 \\
\hline $\begin{array}{l}\text { Campomanesia guazumifolia (Cambess.) O. } \\
\text { Berg }\end{array}$ & Myrtaceae & 04 & 0,0169 & 0,79 & 0,83 & 0,83 & 1,622 & 0,81 & 2,453 & 0,82 \\
\hline Brosimum glaucum Taub. & Moraceae & 04 & 0,0160 & 0,79 & 0,83 & 0,79 & 1,578 & 0,79 & 2,409 & 0,80 \\
\hline Sloanea garckeana K. Schum. & Elaeocarpaceae & 04 & 0,0158 & 0,79 & 0,83 & 0,78 & 1,569 & 0,78 & 2,400 & 0,80 \\
\hline
\end{tabular}




\begin{tabular}{|c|c|c|c|c|c|c|c|c|c|c|}
\hline Neoraputia magnifica (Engl.) Emmerich & Rutaceae & 04 & 0,0154 & 0,79 & 0,83 & 0,76 & 1,546 & 0,77 & 2,377 & 0,79 \\
\hline Inga hispida Schott ex Benth. & Mimosoideae & 04 & 0,0149 & 0,79 & 0,83 & 0,73 & 1,521 & 0,76 & 2,352 & 0,78 \\
\hline Swartzia apetala Raddi & Papilionoideae & 04 & 0,0145 & 0,79 & 0,83 & 0,72 & 1,503 & 0,75 & 2,334 & 0,78 \\
\hline Chamaecrista bahiae (H.S. Irwin) H.S. Irwin & Caesalpinioideae & 04 & 0,0142 & 0,79 & 0,83 & 0,7 & 1,490 & 0,75 & 2,321 & 0,77 \\
\hline Ecclinusa ramiflora Mart. & Sapotaceae & 05 & 0,0158 & 0,98 & 0,55 & 0,78 & 1,763 & 0,88 & 2,317 & 0,77 \\
\hline Dalbergia elegans A.M.V. de Carvalho & Papilionoideae & 04 & 0,0128 & 0,79 & 0,83 & 0,63 & 1,419 & 0,71 & 2,250 & 0,75 \\
\hline Parapiptadenia pterosperma (Bojer) Brenan & Mimosoideae & 04 & 0,0180 & 0,79 & 0,55 & 0,89 & 1,674 & 0,84 & 2,228 & 0,74 \\
\hline Pera leandri Baill. & Euphorbiaceae & 03 & 0,0154 & 0,59 & 0,83 & 0,76 & 1,350 & 0,68 & 2,181 & 0,73 \\
\hline $\begin{array}{l}\text { Pseudopiptadenia contorta (DC.) G.P. Lewis \& } \\
\text { M.P. Lima }\end{array}$ & Mimosoideae & 03 & 0,0145 & 0,59 & 0,83 & 0,72 & 1,308 & 0,65 & 2,139 & 0,71 \\
\hline Albizia polycephala (Benth.) Killip & Mimosoideae & 03 & 0,0134 & 0,59 & 0,83 & 0,66 & 1,253 & 0,63 & 2,084 & 0,69 \\
\hline Eschweilera ovata (Cambess.) Miers & Lecythidaceae & 03 & 0,0176 & 0,59 & 0,55 & 0,87 & 1,457 & 0,73 & 2,011 & 0,67 \\
\hline Platymiscium floribundum Vogel & Papilionoideae & 03 & 0,0117 & 0,59 & 0,83 & 0,58 & 1,169 & 0,58 & 2,000 & 0,67 \\
\hline Pouteria pachycalyx T.D. Penn. & Sapotaceae & 03 & 0,0175 & 0,59 & 0,55 & 0,87 & 1,456 & 0,73 & 2,010 & 0,67 \\
\hline Psidium aff. macrospermum O. Berg & Myrtaceae & 04 & 0,0138 & 0,79 & 0,55 & 0,68 & 1,466 & 0,73 & 2,020 & 0,67 \\
\hline Cordia trichoclada DC. & Boraginaceae & 03 & 0,0164 & 0,59 & 0,55 & 0,81 & 1,399 & 0,70 & 1,953 & 0,65 \\
\hline Allophylus petiolulatus Radlk. & Sapindaceae & 03 & 0,0102 & 0,59 & 0,83 & 0,5 & 1,093 & 0,55 & 1,924 & 0,64 \\
\hline Manilkara bella Monach. & Sapotaceae & 03 & 0,0099 & 0,59 & 0,83 & 0,49 & 1,082 & 0,54 & 1,913 & 0,64 \\
\hline Miconia prasina (Sw.) DC. & Melastomataceae & 04 & 0,0175 & 0,79 & 0,28 & 0,86 & 1,652 & 0,83 & 1,929 & 0,64 \\
\hline Ormosia arborea (Vell.) Harms & Papilionoideae & 03 & 0,0099 & 0,59 & 0,83 & 0,49 & 1,078 & 0,54 & 1,909 & 0,64 \\
\hline $\begin{array}{l}\text { Vatairea heteroptera (Allemão) Ducke ex de } \\
\text { Assis Iglesias }\end{array}$ & Papilionoideae & 03 & 0,0087 & 0,59 & 0,83 & 0,43 & 1,022 & 0,51 & 1,853 & 0,62 \\
\hline Chamaecrista sp. & Caesalpinioideae & 03 & 0,0086 & 0,59 & 0,83 & 0,42 & 1,013 & 0,51 & 1,844 & 0,61 \\
\hline Vismia aff. martiana Reichardt & Hypericaceae & 04 & 0,0158 & 0,79 & 0,28 & 0,78 & 1,567 & 0,78 & 1,844 & 0,61 \\
\hline Casearia arborea (Rich.) Urb. & Salicaceae & 04 & 0,0146 & 0,79 & 0,28 & 0,72 & 1,509 & 0,75 & 1,786 & 0,60 \\
\hline Cordia ecalyculata Vell. & Boraginaceae & 03 & 0,0120 & 0,59 & 0,55 & 0,59 & 1,182 & 0,59 & 1,736 & 0,58 \\
\hline $\begin{array}{l}\text { Handroanthus aff. chrysotrichus (Mart. ex A. } \\
\text { DC.) Mattos }\end{array}$ & Bignoniaceae & 03 & 0,0121 & 0,59 & 0,55 & 0,59 & 1,186 & 0,59 & 1,74 & 0,58 \\
\hline Randia armata (Sw.) DC. & Rubiaceae & 03 & 0,0123 & 0,59 & 0,55 & 0,61 & 1,199 & 0,60 & 1,753 & 0,58 \\
\hline Actinostemon cf. concolor (Spreng.) Müll. Arg. & Euphorbiaceae & 03 & 0,0104 & 0,59 & 0,55 & 0,51 & 1,105 & 0,55 & 1,659 & 0,55 \\
\hline Machaerium ovalifolium Glaz. ex Rudd & Papilionoideae & 04 & 0,0117 & 0,79 & 0,28 & 0,58 & 1,366 & 0,68 & 1,643 & 0,55 \\
\hline Naucleopsis oblongifolia (Kuhlm.) Carauta & Moraceae & 03 & 0,0158 & 0,59 & 0,28 & 0,78 & 1,372 & 0,69 & 1,649 & 0,55 \\
\hline Rutaceae & Rutaceae & 03 & 0,0073 & 0,59 & 0,55 & 0,36 & 0,953 & 0,48 & 1,507 & 0,50 \\
\hline Pouteria cuspidata (A. DC.) Baehni & Sapotaceae & 02 & 0,0107 & 0,39 & 0,55 & 0,53 & 0,921 & 0,46 & 1,475 & 0,49 \\
\hline Tabernaemontana salzmannii A. DC. & Apocynaceae & 02 & 0,0104 & 0,39 & 0,55 & 0,51 & 0,906 & 0,45 & 1,46 & 0,49 \\
\hline Pouteria sp. 1 & Sapotaceae & 03 & 0,0114 & 0,59 & 0,28 & 0,56 & 1,154 & 0,58 & 1,431 & 0,48 \\
\hline $\begin{array}{l}\text { Lonchocarpus cultratus (Vell.) A.M.G. Azevedo } \\
\text { \& H.C. Lima }\end{array}$ & Papilionoideae & 02 & 0,0091 & 0,39 & 0,55 & 0,45 & 0,845 & 0,42 & 1,399 & 0,47 \\
\hline Tapirira guianensis Aubl. & Anacardiaceae & 02 & 0,0096 & 0,39 & 0,55 & 0,47 & 0,867 & 0,43 & 1,421 & 0,47 \\
\hline Apuleia leiocarpa (Vogel) J.F. Macbr. & Caesalpinioideae & 02 & 0,0087 & 0,39 & 0,55 & 0,43 & 0,821 & 0,41 & 1,375 & 0,46 \\
\hline Aspidosperma parvifolium A. DC. & Apocynaceae & 02 & 0,0086 & 0,39 & 0,55 & 0,42 & 0,818 & 0,41 & 1,372 & 0,46 \\
\hline
\end{tabular}




\begin{tabular}{|c|c|c|c|c|c|c|c|c|c|c|}
\hline Centrolobium sclerophyllum H.C. Lima & Papilionoideae & 02 & 0,0085 & 0,39 & 0,55 & 0,42 & 0,815 & 0,41 & 1,369 & 0,46 \\
\hline Pouteria bangii (Rusby) T.D. Penn. & Sapotaceae & 02 & 0,0090 & 0,39 & 0,55 & 0,45 & 0,840 & 0,42 & 1,394 & 0,46 \\
\hline Pouteria sp. 3 & Sapotaceae & 02 & 0,0087 & 0,39 & 0,55 & 0,43 & 0,821 & 0,41 & 1,375 & 0,46 \\
\hline Calyptranthes sp. & Myrtaceae & 03 & 0,0099 & 0,59 & 0,28 & 0,49 & 1,079 & 0,54 & 1,356 & 0,45 \\
\hline $\begin{array}{l}\text { Senna multijuga var. verrucosa (Vogel) H.S. } \\
\text { Irwin }\end{array}$ & Caesalpinioideae & 02 & 0,0135 & 0,39 & 0,28 & 0,66 & 1,058 & 0,53 & 1,335 & 0,45 \\
\hline Citronella paniculata (Mart.) R.A. Howard & Cardiopteridaceae & 02 & 0,0066 & 0,39 & 0,55 & 0,33 & 0,722 & 0,36 & 1,276 & 0,43 \\
\hline Couratari asterotricha Prance & Lecythidaceae & 02 & 0,0068 & 0,39 & 0,55 & 0,34 & 0,731 & 0,37 & 1,285 & 0,43 \\
\hline Exostyles venusta Schott ex Spreng. & Papilionoideae & 02 & 0,0069 & 0,39 & 0,55 & 0,34 & 0,736 & 0,37 & 1,29 & 0,43 \\
\hline $\begin{array}{l}\text { Hymenaea courbaril var. stilbocarpa (Hayne) } \\
\text { Y.T. Lee }\end{array}$ & Caesalpinioideae & 02 & 0,0066 & 0,39 & 0,55 & 0,33 & 0,721 & 0,36 & 1,275 & 0,43 \\
\hline Lauraceae & Lauraceae & 02 & 0,0066 & 0,39 & 0,55 & 0,33 & 0,722 & 0,36 & 1,276 & 0,43 \\
\hline Piptadenia paniculata Benth. & Mimosoideae & 02 & 0,0061 & 0,39 & 0,55 & 0,3 & 0,695 & 0,35 & 1,249 & 0,42 \\
\hline Pseudima frutescens (Aubl.) Radlk. & Sapindaceae & 02 & 0,0061 & 0,39 & 0,55 & 0,3 & 0,697 & 0,35 & 1,251 & 0,42 \\
\hline Astronium graveolens Jacq. & Anacardiaceae & 02 & 0,0056 & 0,39 & 0,55 & 0,28 & 0,670 & 0,33 & 1,224 & 0,41 \\
\hline Pouteria aff. hispida Eyma & Sapotaceae & 02 & 0,0057 & 0,39 & 0,55 & 0,28 & 0,676 & 0,34 & 1,23 & 0,41 \\
\hline $\begin{array}{l}\text { Swartzia myrtifolia var. elegans (Schott) R.S. } \\
\text { Cowan }\end{array}$ & Papilionoideae & 02 & 0,0057 & 0,39 & 0,55 & 0,28 & 0,674 & 0,34 & 1,228 & 0,41 \\
\hline Aparisthmium cordatum Baill. & Euphorbiaceae & 02 & 0,0109 & 0,39 & 0,28 & 0,54 & 0,931 & 0,47 & 1,208 & 0,40 \\
\hline Dialium guianense (Aubl.) Sandwith & Caesalpinioideae & 02 & 0,0054 & 0,39 & 0,55 & 0,26 & 0,658 & 0,33 & 1,212 & 0,40 \\
\hline Marlierea sucrei G.M. Barroso \& Peixoto & Myrtaceae & 02 & 0,0048 & 0,39 & 0,55 & 0,24 & 0,633 & 0,32 & 1,187 & 0,40 \\
\hline Sapindaceae & Myrtaceae & 02 & 0,0052 & 0,39 & 0,55 & 0,25 & 0,648 & 0,32 & 1,202 & 0,40 \\
\hline Solanum sooretamum Carvalho & Solanaceae & 02 & 0,0050 & 0,39 & 0,55 & 0,25 & 0,640 & 0,32 & 1,194 & 0,40 \\
\hline Pouteria coelomatica Rizzini & Sapotaceae & 02 & 0,0040 & 0,39 & 0,55 & 0,2 & 0,590 & 0,29 & 1,144 & 0,38 \\
\hline Melanopsidium nigrum Colla & Rubiaceae & 02 & 0,0092 & 0,39 & 0,28 & 0,45 & 0,848 & 0,42 & 1,125 & 0,37 \\
\hline Eugenia sp. 2 & Myrtaceae & 02 & 0,0086 & 0,39 & 0,28 & 0,42 & 0,817 & 0,41 & 1,094 & 0,36 \\
\hline Vismia ferruginea Kunth & Hypericaceae & 02 & 0,0083 & 0,39 & 0,28 & 0,41 & 0,802 & 0,40 & 1,079 & 0,36 \\
\hline Solanum pseudoquina A. St.-Hil. & Solanaceae & 02 & 0,0079 & 0,39 & 0,28 & 0,39 & 0,781 & 0,39 & 1,058 & 0,35 \\
\hline Inga aff. cylindrica (Vell.) Mart. & Mimosoideae & 02 & 0,0069 & 0,39 & 0,28 & 0,34 & 0,736 & 0,37 & 1,013 & 0,34 \\
\hline Marlierea sp. & Myrtaceae & 02 & 0,0069 & 0,39 & 0,28 & 0,34 & 0,736 & 0,37 & 1,013 & 0,34 \\
\hline Sapotaceae 2 & Sapotaceae & 02 & 0,0071 & 0,39 & 0,28 & 0,35 & 0,745 & 0,37 & 1,022 & 0,34 \\
\hline Cordia acutifolia Fresen. & Boraginaceae & 02 & 0,0066 & 0,39 & 0,28 & 0,32 & 0,718 & 0,36 & 0,995 & 0,33 \\
\hline Eugenia rostrata $\mathrm{O}$. Berg & Myrtaceae & 02 & 0,0067 & 0,39 & 0,28 & 0,33 & 0,724 & 0,36 & 1,001 & 0,33 \\
\hline Micropholis sp. & Sapotaceae & 01 & 0,0104 & 0,20 & 0,28 & 0,51 & 0,709 & 0,35 & 0,986 & 0,33 \\
\hline Sapotaceae 1 & Sapotaceae & 02 & 0,0068 & 0,39 & 0,28 & 0,33 & 0,728 & 0,36 & 1,005 & 0,33 \\
\hline Eugenia excelsa O. Berg & Myrtaceae & 02 & 0,0061 & 0,39 & 0,28 & 0,3 & 0,693 & 0,35 & 0,970 & 0,32 \\
\hline Mabea sp. & Euphorbiaceae & 02 & 0,0059 & 0,39 & 0,28 & 0,29 & 0,685 & 0,34 & 0,962 & 0,32 \\
\hline Eugenia sp. 1 & Myrtaceae & 02 & 0,0055 & 0,39 & 0,28 & 0,27 & 0,667 & 0,33 & 0,944 & 0,31 \\
\hline Geissospermum laeve (Vell.) Miers & Apocynaceae & 01 & 0,0092 & 0,20 & 0,28 & 0,46 & 0,653 & 0,33 & 0,93 & 0,31 \\
\hline Sloanea eichleri K. Schum. & Elaeocarpaceae & 02 & 0,0054 & 0,39 & 0,28 & 0,27 & 0,659 & 0,33 & 0,936 & 0,31 \\
\hline
\end{tabular}




\begin{tabular}{|c|c|c|c|c|c|c|c|c|c|c|}
\hline Erythroxylum sp. & Erythroxylaceae & 02 & 0,0040 & 0,39 & 0,28 & 0,2 & 0,589 & 0,29 & 0,866 & 0,29 \\
\hline Andira anthelmia (Vell.) J.F. Macbr. & Papilionoideae & 01 & 0,0072 & 0,20 & 0,28 & 0,35 & 0,550 & 0,28 & 0,827 & 0,28 \\
\hline Zanthoxylum rhoifolium var. petiolulatum Engl. & Rutaceae & 01 & 0,0074 & 0,20 & 0,28 & 0,37 & 0,562 & 0,28 & 0,839 & 0,28 \\
\hline Ficus gomelleira Kunth \& C.D. Bouché & Moraceae & 01 & 0,0067 & 0,20 & 0,28 & 0,33 & 0,527 & 0,26 & 0,804 & 0,27 \\
\hline Jacaratia heptaphylla (Vell.) A. DC. & Caricaceae & 01 & 0,0067 & 0,20 & 0,28 & 0,33 & 0,529 & 0,26 & 0,806 & 0,27 \\
\hline Unonopsis aurantiaca Maas \& Westra & Annonaceae & 01 & 0,0066 & 0,20 & 0,28 & 0,33 & 0,525 & 0,26 & 0,802 & 0,27 \\
\hline Chrysobalanaceae & Chrysobalanaceae & 01 & 0,0062 & 0,20 & 0,28 & 0,31 & 0,505 & 0,25 & 0,782 & 0,26 \\
\hline Pouteria venosa subsp. amazonica T.D. Penn. & Sapotaceae & 01 & 0,0060 & 0,20 & 0,28 & 0,3 & 0,494 & 0,25 & 0,771 & 0,26 \\
\hline Manilkara salzmannii (A. DC.) H.J. Lam & Sapotaceae & 01 & 0,0054 & 0,20 & 0,28 & 0,27 & 0,463 & 0,23 & 0,740 & 0,25 \\
\hline Ampelocera glabra Kuhlm. & Ulmaceae & 01 & 0,0052 & 0,20 & 0,28 & 0,26 & 0,452 & 0,23 & 0,729 & 0,24 \\
\hline Cedrela fissilis Vell. & Meliaceae & 01 & 0,0048 & 0,20 & 0,28 & 0,24 & 0,433 & 0,22 & 0,710 & 0,24 \\
\hline Chomelia pubescens Cham. \& Schltdl. & Rubiaceae & 01 & 0,0047 & 0,20 & 0,28 & 0,23 & 0,431 & 0,22 & 0,708 & 0,24 \\
\hline Coccoloba sp. & Polygonaceae & 01 & 0,0052 & 0,20 & 0,28 & 0,26 & 0,452 & 0,23 & 0,729 & 0,24 \\
\hline Enterolobium glaziovii (Benth.) Mesquita & Mimosoideae & 01 & 0,0048 & 0,20 & 0,28 & 0,24 & 0,432 & 0,22 & 0,709 & 0,24 \\
\hline Hirtella sprucei Benth.ex Hook.f. & Chrysobalanaceae & 01 & 0,0048 & 0,20 & 0,28 & 0,24 & 0,433 & 0,22 & 0,71 & 0,24 \\
\hline Macrothumia kuhlmannii (Sleumer) Alford & Salicaceae & 01 & 0,0047 & 0,20 & 0,28 & 0,23 & 0,431 & 0,22 & 0,708 & 0,24 \\
\hline Ocotea sp. 2 & Lauraceae & 01 & 0,0049 & 0,20 & 0,28 & 0,24 & 0,438 & 0,22 & 0,715 & 0,24 \\
\hline Pouteria sp. 2 & Sapotaceae & 01 & 0,0050 & 0,20 & 0,28 & 0,25 & 0,443 & 0,22 & 0,72 & 0,24 \\
\hline Ravenia infelix Vell. & Rutaceae & 01 & 0,0052 & 0,20 & 0,28 & 0,26 & 0,452 & 0,23 & 0,729 & 0,24 \\
\hline Senna sp. & Caesalpinioideae & 01 & 0,0050 & 0,20 & 0,28 & 0,25 & 0,443 & 0,22 & 0,720 & 0,24 \\
\hline Sparattosperma leucanthum (Vell.) K. Schum. & Bignoniaceae & 01 & 0,0051 & 0,20 & 0,28 & 0,25 & 0,448 & 0,22 & 0,725 & 0,24 \\
\hline Diospyros capreifolia Mart. ex Hiern & Ebenaceae & 01 & 0,0046 & 0,20 & 0,28 & 0,23 & 0,426 & 0,21 & 0,703 & 0,23 \\
\hline Margaritaria nobilis L. f. & Phyllanthaceae & 01 & 0,0046 & 0,20 & 0,28 & 0,23 & 0,423 & 0,21 & 0,700 & 0,23 \\
\hline Myrtaceae & Myrtaceae & 01 & 0,0045 & 0,20 & 0,28 & 0,22 & 0,417 & 0,21 & 0,694 & 0,23 \\
\hline Pouteria aff. filipes Eyma & Sapotaceae & 01 & 0,0042 & 0,20 & 0,28 & 0,21 & 0,405 & 0,20 & 0,682 & 0,23 \\
\hline Alchornea iricurana Casar. & Euphorbiaceae & 01 & 0,0036 & 0,20 & 0,28 & 0,18 & 0,374 & 0,19 & 0,651 & 0,22 \\
\hline Cordia sp. & Boraginaceae & 01 & 0,0036 & 0,20 & 0,28 & 0,18 & 0,377 & 0,19 & 0,654 & 0,22 \\
\hline Cupania sp. 1 & Sapindaceae & 01 & 0,0035 & 0,20 & 0,28 & 0,17 & 0,370 & 0,18 & 0,647 & 0,22 \\
\hline Heisteria ovata Benth. & Olacaceae & 01 & 0,0038 & 0,20 & 0,28 & 0,19 & 0,387 & 0,19 & 0,664 & 0,22 \\
\hline Picramnia sellowii Planch. & Picramniaceae & 01 & 0,0038 & 0,20 & 0,28 & 0,19 & 0,384 & 0,19 & 0,661 & 0,22 \\
\hline Qualea megalocarpa Stafleu & Vochysiaceae & 01 & 0,0035 & 0,20 & 0,28 & 0,17 & 0,370 & 0,18 & 0,647 & 0,22 \\
\hline Cupania sp. 2 & Sapindaceae & 01 & 0,0040 & 0,20 & 0,28 & 0,2 & 0,392 & 0,20 & 0,669 & 0,22 \\
\hline Brosimum glaziovii Taub. & Moraceae & 01 & 0,0033 & 0,20 & 0,28 & 0,16 & 0,360 & 0,18 & 0,637 & 0,21 \\
\hline Casearia sp. & Salicaceae & 01 & 0,0029 & 0,20 & 0,28 & 0,14 & 0,339 & 0,17 & 0,616 & 0,21 \\
\hline Coccoloba warmingii Meisn. & Polygonaceae & 01 & 0,0031 & 0,20 & 0,28 & 0,15 & 0,348 & 0,17 & 0,625 & 0,21 \\
\hline Couepia schottii Fritsch & Chrysobalanaceae & 01 & 0,0032 & 0,20 & 0,28 & 0,16 & 0,354 & 0,18 & 0,631 & 0,21 \\
\hline Coussarea contracta (Walp.) Müll. Arg. & Rubiaceae & 01 & 0,0029 & 0,20 & 0,28 & 0,14 & 0,339 & 0,17 & 0,616 & 0,21 \\
\hline Coussarea sp. & Rubiaceae & 01 & 0,0030 & 0,20 & 0,28 & 0,15 & 0,345 & 0,17 & 0,622 & 0,21 \\
\hline
\end{tabular}




\begin{tabular}{|c|c|c|c|c|c|c|c|c|c|c|}
\hline Cryptocarya citriformis (Vell.) P.L.R. de Moraes & Lauraceae & 01 & 0,0032 & 0,20 & 0,28 & 0,16 & 0,357 & 0,18 & 0,634 & 0,21 \\
\hline Exellodendron gracile (Kuhlm.) Prance & Chrysobalanaceae & 01 & 0,0033 & 0,20 & 0,28 & 0,16 & 0,359 & 0,18 & 0,636 & 0,21 \\
\hline Ficus sp. & Moraceae & 01 & 0,0029 & 0,20 & 0,28 & 0,14 & 0,339 & 0,17 & 0,616 & 0,21 \\
\hline Guapira noxia (Netto) Lundell & Nyctaginaceae & 01 & 0,0029 & 0,20 & 0,28 & 0,14 & 0,342 & 0,17 & 0,619 & 0,21 \\
\hline Guazuma crinita Mart. & Malvaceae & 01 & 0,0031 & 0,20 & 0,28 & 0,15 & 0,351 & 0,18 & 0,628 & 0,21 \\
\hline $\begin{array}{l}\text { Handroanthus riodocensis (A.H. Gentry) S. O. } \\
\text { Grose }\end{array}$ & Bignoniaceae & 01 & 0,0032 & 0,20 & 0,28 & 0,16 & 0,354 & 0,18 & 0,631 & 0,21 \\
\hline Monimiaceae & Monimiaceae & 01 & 0,0031 & 0,20 & 0,28 & 0,16 & 0,352 & 0,18 & 0,629 & 0,21 \\
\hline Myrcia eumecephylla (O. Berg) Nied. & Myrtaceae & 01 & 0,0033 & 0,20 & 0,28 & 0,17 & 0,362 & 0,18 & 0,639 & 0,21 \\
\hline Trichilia $\mathrm{sp}$. & Meliaceae & 01 & 0,0030 & 0,20 & 0,28 & 0,15 & 0,343 & 0,17 & 0,620 & 0,21 \\
\hline Aspidosperma desmanthum Benth. ex Müll. Arg. & Apocynaceae & 01 & 0,0027 & 0,20 & 0,28 & 0,13 & 0,331 & 0,17 & 0,608 & 0,20 \\
\hline Casearia commersoniana Cambess. & Salicaceae & 01 & 0,0023 & 0,20 & 0,28 & 0,11 & 0,310 & 0,16 & 0,587 & 0,20 \\
\hline $\begin{array}{l}\text { Chrysophyllum gonocarpum (Mart. \& Eichler } \\
\text { ex Miq.) }\end{array}$ & Sapotaceae & 01 & 0,0025 & 0,20 & 0,28 & 0,12 & 0,320 & 0,16 & 0,597 & 0,20 \\
\hline Clarisia ilicifolia (Spreng.) Lanj. \& Rossberg & Moraceae & 01 & 0,0023 & 0,20 & 0,28 & 0,11 & 0,309 & 0,15 & 0,586 & 0,20 \\
\hline Papilionoideae & Papilionoideae & 01 & 0,0028 & 0,20 & 0,28 & 0,14 & 0,335 & 0,17 & 0,613 & 0,20 \\
\hline Micropholis gardneriana (A. DC.) Pierre & Sapotaceae & 01 & 0,0028 & 0,20 & 0,28 & 0,14 & 0,335 & 0,17 & 0,613 & 0,20 \\
\hline Neea floribunda Poepp. \& Endl. & Nyctaginaceae & 01 & 0,0023 & 0,20 & 0,28 & 0,12 & 0,313 & 0,16 & 0,590 & 0,20 \\
\hline Pera glabrata (Schott) Poepp. ex Baill. & Euphorbiaceae & 01 & 0,0028 & 0,20 & 0,28 & 0,14 & 0,333 & 0,17 & 0,610 & 0,20 \\
\hline Protium heptaphyllum (Aubl.) Marchand & Burseraceae & 01 & 0,0024 & 0,20 & 0,28 & 0,12 & 0,317 & 0,16 & 0,594 & 0,20 \\
\hline Xylosma sp. & Salicaceae & 01 & 0,0023 & 0,20 & 0,28 & 0,12 & 0,313 & 0,16 & 0,590 & 0,20 \\
\hline Amphirrhox longifolia (A. St.-Hil.) Spreng. & Violaceae & 01 & 0,0021 & 0,20 & 0,28 & 0,10 & 0,300 & 0,15 & 0,577 & 0,19 \\
\hline Amphirrhox sp. & Violaceae & 01 & 0,0022 & 0,20 & 0,28 & 0,11 & 0,308 & 0,15 & 0,585 & 0,19 \\
\hline Capparis nectaria Vell. & Capparaceae & 01 & 0,0021 & 0,20 & 0,28 & 0,10 & 0,300 & 0,15 & 0,577 & 0,19 \\
\hline Faramea sp. & Rubiaceae & 01 & 0,0020 & 0,20 & 0,28 & 0,10 & 0,297 & 0,15 & 0,574 & 0,19 \\
\hline Genipa americana $\mathrm{L}$. & Rubiaceae & 01 & 0,0021 & 0,20 & 0,28 & 0,11 & 0,302 & 0,15 & 0,58 & 0,19 \\
\hline Grazielodendron riodocensis H.C. Lima & Papilionoideae & 01 & 0,0021 & 0,20 & 0,28 & 0,10 & 0,301 & 0,15 & 0,578 & 0,19 \\
\hline Hirtella insignis Briq. ex Prance & Chrysobalanaceae & 01 & 0,0021 & 0,20 & 0,28 & 0,10 & 0,301 & 0,15 & 0,578 & 0,19 \\
\hline Joannesia princeps Vell. & Euphorbiaceae & 01 & 0,0020 & 0,20 & 0,28 & 0,10 & 0,296 & 0,15 & 0,573 & 0,19 \\
\hline Miconia cf. cinnamomifolia (DC.) Naudin & Melastomataceae & 01 & 0,0020 & 0,20 & 0,28 & 0,10 & 0,295 & 0,15 & 0,572 & 0,19 \\
\hline Myrcia follii G.M. Barroso \& Peixoto & Myrtaceae & 01 & 0,0020 & 0,20 & 0,28 & 0,10 & 0,297 & 0,15 & 0,574 & 0,19 \\
\hline Ocotea nitida (Meisn.) Rohwer & Myrtaceae & 01 & 0,0022 & 0,20 & 0,28 & 0,11 & 0,307 & 0,15 & 0,584 & 0,19 \\
\hline Parinari parvifolia Sandwith & Lauraceae & 01 & 0,0022 & 0,20 & 0,28 & 0,11 & 0,305 & 0,15 & 0,582 & 0,19 \\
\hline Simira sp. & Rubiaceae & 01 & 0,0020 & 0,20 & 0,28 & 0,10 & 0,297 & 0,15 & 0,574 & 0,19 \\
\hline Swartzia oblata R.S. Cowan & Papilionoideae & 01 & 0,0022 & 0,20 & 0,28 & 0,11 & 0,304 & 0,15 & 0,581 & 0,19 \\
\hline Terminalia glabrescens Mart. & Combretaceae & 01 & 0,0020 & 0,20 & 0,28 & 0,10 & 0,294 & 0,15 & 0,571 & 0,19 \\
\hline Tovomita brevistaminea Engl. & Clusiaceae & 01 & 0,0022 & 0,20 & 0,28 & 0,11 & 0,305 & 0,15 & 0,582 & 0,19 \\
\hline $\begin{array}{l}\text { Trichilia lepidota subsp. schumanniana (Harms) } \\
\text { T.D. Penn. }\end{array}$ & Meliaceae & 01 & 0,0020 & 0,20 & 0,28 & 0,10 & 0,294 & 0,15 & 0,571 & 0,19 \\
\hline Total & & 500 & 2,0257 & 100 & 100 & 100 & 200 & 100 & 300 & 100 \\
\hline
\end{tabular}


$\mathrm{Na}$ amostragem, nove espécies estão na lista da IUCN (2009), 11 espécies constam na Lista Oficial das Espécies da Flora Brasileira Ameaçadas de Extinção (MMA, 2008), 13 espécies estão presentes na Lista de Espécies Ameaçadas de Extinção no Espírito Santo (ESPÍRITO SANTO, 2005) e sete espécies são encontradas na Lista de plantas raras do Brasil segundo Giulietti et al. (2009). Esses autores dizem que são as espécies raras, especialmente aquelas com distribuição bastante restrita, as mais suscetíveis a distúrbios antrópicos ou eventos estocásticos naturais. Por isso, devem ser tratadas como vulneráveis. Das espécies ameaçadas da lista estadual, cinco são consideradas vulneráveis (Capparis nectaria, Sloanea garckeana, Ocotea confertiflora, Myrcia follii e Grazielodendron riodocensis), seis estão em perigo (Exellodendron gracile, Couratari asterotricha, Marlierea sucrei, Centrolobium sclerophyllum, Machaerium fulvovenosum e Solanum sooretamum) e duas estão criticamente em perigo (Caesalpinia echinata e Melanoxylon brauna). As espécies Couratari asterotricha e Caesalpinia echinata estão nas três listas de plantas ameaçadas de extinção, sendo que Couratari asterotricha também está na lista de plantas raras (Tabela 2).

\section{Diversidade e similaridade de espécies}

O índice de diversidade de Shannon ( $\left.\mathrm{H}^{\prime}\right)$ encontrado foi de 4,89, com um valor da equabilidade (J) de 0,94 . Entre as parcelas os valores de diversidade de espécies variaram de 3,29 a 3,65, com os valores dos índices de similaridade das unidades amostrais variando entre $8 \%$ e $24 \%$ (Figura 4 ).

\section{Discussão}

\section{Estrutura da floresta}

$\mathrm{O}$ valor de área basal total encontrado foi baixo $\left(4,0 \mathrm{~m}^{2} \cdot \mathrm{ha}^{-1}\right)$ em comparação com outras Florestas de Tabuleiros, tais como em Sooretama (ES) com 47,1 $\mathrm{m}^{2}$. ha $^{-1}$ (PAULA, 2006) e na Mata do Carvão (RJ) com $15 \mathrm{~m}^{2} \cdot \mathrm{ha}^{-1}$ (SILVA; NASCIMENTO, 2001), isso se deve ao fato do critério de inclusão adotado e também, provavelmente, ao corte seletivo. A área em volta do fragmento foi bastante reduzida no passado devido a desmatamentos para plantio de eucalipto, de limão, de pastagens e outros impactos antrópicos, seguindo o padrão geral de degradação observado para as matas do domínio atlântico (GIULIETTI; FORERO, 1990).

FIGURA 4: Similaridade florística entre as dez unidades amostrais amostradas na AI do Limão, Aracruz, ES.

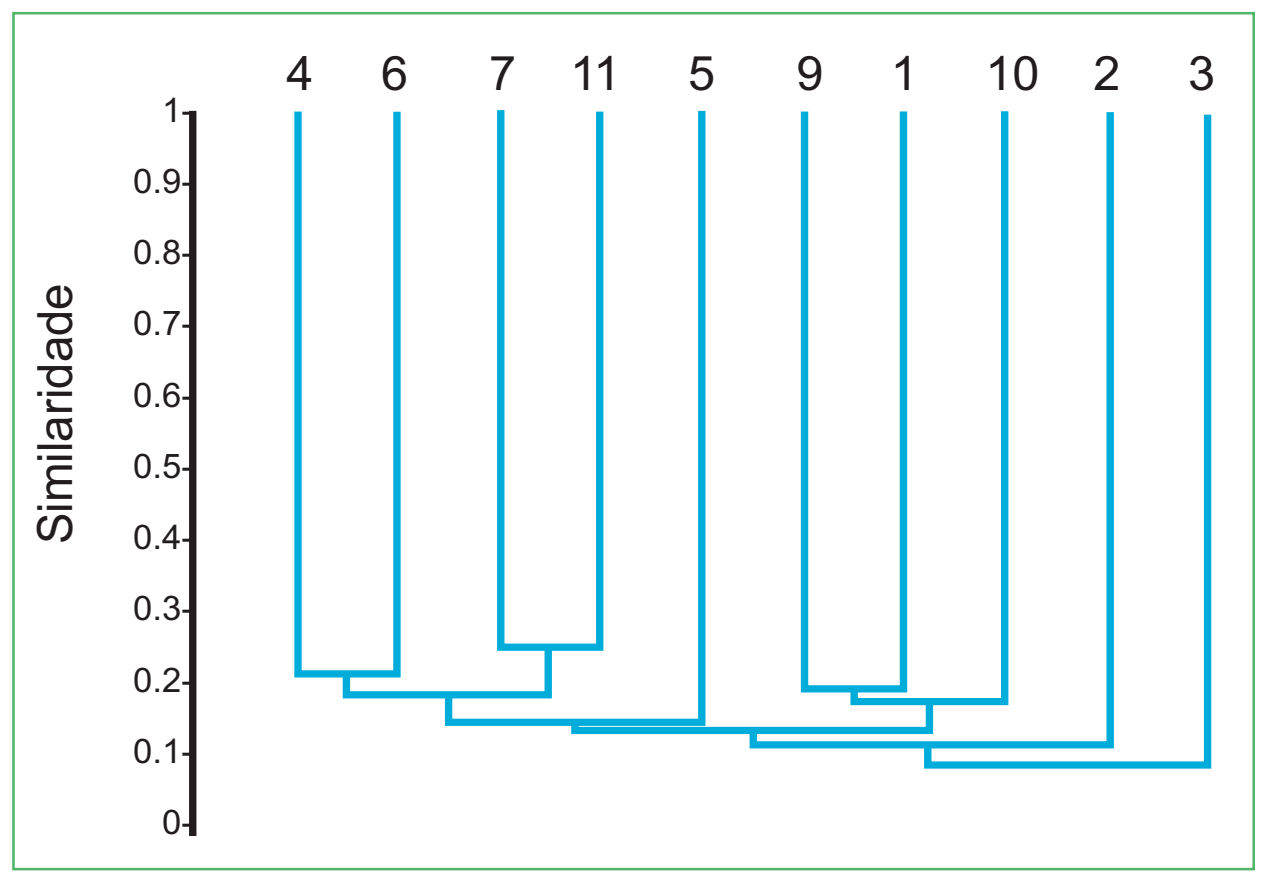


$\mathrm{Na}$ distribuição diamétrica incluindo todas as espécies amostradas, não é possível definir com clareza o padrão de distribuição dos indivíduos uma vez que o estrato analisado corresponde a um pequeno intervalo de DAP (DAP $\geq 5 \mathrm{~cm}$ e $<10 \mathrm{~cm}$ ). Mas pode se afirmar que para a comunidade no estrato analisado, um maior número de representantes nas classes inferiores talvez indique que a maioria das populações está em fase inicial de estabelecimento (SILVA-JUNIOR, 1984). A distribuição diamétrica de Caesalpinia echinata, Eugenia tinguyensis e Pterocarpus rohrii mesmo que irregular, pode estar indicando que elas representem espécies com populações jovens, com distribuição ainda pouco ampla, mas com representações satisfatórias nas classes de DAP analisadas.

\section{Aspectos florísticosefitossociológicos}

As famílias mais ricas em espécies, Leguminosae, Sapotaceae e Myrtaceae confirmam o padrão de riqueza para costa brasileira (MORI et al., 1983; PEIXOTO; GENTRY, 1990). Em segundo lugar de riqueza de espécies está Sapotaceae, corroborando Gentry (1988) que indicou esta família entre as com maiores riquezas de espécies para as florestas neotropicais.

De acordo com Richards (1981), a dominância por família, que consiste na preponderância numérica de espécies de uma mesma família, parece ser uma característica comum de florestas tropicais. Embora não se possa falar de uma nítida dominância de Leguminosae na mata estudada, esta família apresenta grande destaque em relação às demais, possuindo quase que o dobro de espécies de Sapotaceae.

As $41,3 \%$ espécies que ocorreram com apenas um indivíduo na amostragem podem ser consideradas como raras segundo Martins (1993). Esse valor (41,3\%) está acima dos encontrados por [lc.,] quando comparou algumas florestas brasileiras quanto a este parâmetro, tendo encontrado valores que variaram de 9,2\% a 39,5\% para áreas de Florestas Atlânticas. Martins (1993) ressaltou ainda que a proporção elevada de espécies raras contribui para a semelhança dos valores mais baixos de importância e também a diversidade de espécies pode implicar na insignificância relativa de grande parte delas, ou seja, cada espécie contribui com um valor de importância muito baixo.

Caesalpinia echinata apresentou o maior valor de importância (VI) fitossociológica e vale ressaltar que essa representa a única população nativa dessa espécie que se tem conhecimento no Estado, e a mesma encontrase com altos valores de VI, o que reforça a importância da conservação de pequenos fragmentos com a presença dessa espécie (RODRIGUES et al., 2009). O grande número de plântulas de pau-brasil observadas no fragmento se deve à alta disponibilidade de luz em alguns trechos com clareiras. Isso, segundo Lima et al. (2002), é um indício de que a intensidade da luz em lugares mais abertos da floresta influencia positivamente as taxas de crescimento do pau-brasil. Esse autor revela ainda que se trata de uma árvore que poderia desempenhar muito bem o papel de colonizadora em trechos degradados nas bordas de florestas. Em relação à composição florística, foi observado que das 141 espécies identificadas nas parcelas amostradas, 92 espécies $(63,4 \%)$ constam na lista de espécies que ocorrem em Linhares (ROLIM, 2006) (Tabela 2). Algumas espécies como Protium heptaphyllum, Eugenia excelsa, Guapira opposita, Exostyles venusta, Pouteria coelomatica são comuns nos trabalhos citados na Tabela 3. Ao contrário de Capparis nectaria que ocorre apenas na AI do Limão e

TABELA 3: Número e percentagem de espécies amostradas da AI do Limão que ocorrem em outras matas da região sudeste. Baseado nas 145 espécies identificadas para a AI do Limão, Aracruz/ES.

\begin{tabular}{l|l|c|c|c}
\hline \multicolumn{1}{c|}{ Localidade } & \multicolumn{1}{|c|}{ Tipo florestal } & No de espécies & \% de espécies & Fonte \\
\hline Linhares - ES & Floresta Estacional Semidecidual de Terras Baixas & 92 & 63,4 & Rolim, (2006) \\
Sooretama - ES & Floresta Ombrófila Densa de Terras Baixas & 73 & 50,3 & Paula, (2005) \\
Santa Teresa - ES & Floresta Ombrófila Densa Montana & 40 & 27,5 & Saiter, (2011) \\
Linhares - ES & Floresta Ombrófila Densa Aluvial & 32 & 22 & Gomes, (2006) \\
Setiba - ES & Floresta de Restinga & 10 & 6,9 & Assis, (2003) \\
\hline
\end{tabular}


ainda está na lista de espécies ameaçadas no estado do Espírito Santo, reforçando, mais uma vez, a importância da conservação desse pequeno fragmento.

\section{Diversidade e similaridade de espécies}

No fragmento amostrado o índice de diversidade de Shannon (H') foi de 4,89, sendo este valor bastante expressivo em comparação a outros trabalhos com DAP acima de 5cm como Thomaz (1996) com 5,51 para Santa Teresa (ES), Paula (2006) com 4,87 para Sooretama (ES) e Kurtz et al. (2009) com 3,6 para Armação de Búzios (RJ). Segundo Mantovani (1993), vários são os fatores que podem interferir no índice de diversidade, ressaltando-se o método de amostragem e o critério de inclusão dos indivíduos.

A diversidade é um reflexo de dois parâmetros que são a riqueza em espécies e a equabilidade (que está relacionada com a contribuição numérica relativa de cada espécie). Com isso, no presente trabalho pode-se dizer que a riqueza em espécies (181) e a equabilidade ( $\mathrm{J}=$ $0,94)$ contribuem para o expressivo índice de Shannon encontrado $\left(H^{\prime}=4,98\right)$.

Devido à baixa similaridade florística encontrada entre as unidades amostrais pode-se falar em uma heterogeneidade florística da área, ocorrendo poucas formações de grupos fazendo com que todas as unidades amostrais contribuam para a expressiva diversidade da área. Essa heterogeneidade (Figura 4) pode ser atribuída a alguns fatores como o número elevado de espécies representadas por um ou poucos indivíduos (PAGANO et al., 1995). Portanto, para todos os parâmetros fitossociológicos analisados, a grande maioria das espécies apresenta valores baixos e semelhantes, refletindo a pequena contribuição de cada espécie para a estrutura do fragmento. Este é um padrão característico de florestas tropicais, que tem sido encontrado em florestas brasileiras (KURTZ; ARAÚJO, 2000).

Esse trabalho reforça a ideia da conservação de pequenos fragmentos, que segundo Rodrigues et al. (2009) é de extrema importância, porque se o fragmento é excluído, a população inteira de algumas espécies pode entrar em declínio, levando à extinção de espécies locais, principalmente em se tratando de Caesalpinia echinata, espécie considerada em vias extinção, e que, para o Espírito Santo, até o momento, trata-se da única população nativa que se tem conhecimento e no local de estudo, essa população encontra-se bem preservada e em regeneração, com isso ao se preservar o pau-brasil, conservam-se também os fragmentos de Floresta Atlântica que ainda existem em solo capixaba. Fragmentos como esse estudado são muito importantes tanto pela grande riqueza de espécies que apresenta, quanto pela quantidade de espécies ameaçadas de extinção e de espécies raras que possuem.

\section{Agradecimentos}

Os autores agradecem a UFES, a FIBRIA, ao Herbário VIES e a todos os colegas que se disponibilizaram no auxílio do trabalho a campo.

\section{Referências}

AMADOR, E. S. O. Barreiras do pleistoceno no estado do Espírito Santo e seu relacionamento com depósitos de minerais pesados. In: CONGRESSO BRASILEIRO DE GEOLOGIA, 32, 1982, Salvador. Anais... Salvador: SBGEO, v. 4, p. 1462-1472, 1982.

ANA - AGÊNCIA NACIONAL DAS ÁGUAS. 2010. Disponível em: $<$ http://200.140.135.132/PortalSuporte/frmDadosEstacao.asp $\mathrm{x}$ ? estacao $=1940022 \&$ Ano $=2010 \&$ tipo $=$ Chuvas $>$. Acesso em: 14 abr. 2011.

APG III - THE ANGIOSPERM PHYLOGENY GROUP. An update of the Angiosperm Phylogeny Group classification for the orders and families of flowering plants: APG III. Botanical Journal of the Linnean Society, London, v. 161, p. 105-121, 2009.

BRASIL. Ministério de Minas e Energia. Secretaria Geral. Projeto RADAMBRASIL. Folha SE. 24 Rio Doce; geologia, geomorfologia, pedologia, vegetação e uso potencial da terra. Rio de Janeiro: MMA, 1987. 544 p.

BROWER, J. E.; ZAR, J. H. Field and laboratory methods for general ecology. Boston: W. C. Brown Company Publishers, 1977. $226 \mathrm{p}$.

CARDOSO, M. A.; PROVAN, J.; POWELL, W.; FERREIRA, P. C. G.; OLIVEIRA, D. E. High genetic differentiation among remnant populations of the endangered Caesalpinia echinata Lam. (Leguminosae - Caesalpinioideae). Molecular Ecology, Vancouver, v. 7, p. 601-608, 1998.

CARVALHO, P. E. R. Espécies florestais brasileiras: recomendações silviculturais, potencialidades e uso de madeira. Colombo; Brasília: EMBRAPA-CNPF; EMBRAPA-SPI, 1994. $640 \mathrm{p}$.

CIENTEC. Sistema para análise fitossociológica e elaboração de planos de manejo de florestas nativas. Viçosa: CIENTEC, 2006. CD-ROM. 
EMBRAPA. Levantamento generalizado e semidetalhado de solos da Aracruz Celulose S.A. no Espírito Santo e no extremo sul do estado da Bahia e sua aplicação aos plantios de eucaliptos. Rio de Janeiro: Embrapa, 2000. 93 p.

ESPÍRITO SANTO. Decreto Estadual no 1499-R, de 14 de junho de 2005.

FIDALGO, O.; BONONI, V. L. Técnicas de coleta, preservação e herborização de material botânico. São Paulo: Instituto de Botânica (Manual n. 4), 1984. 62 p.

GENTRY, A. H. Changes in plant community diversity and floristic composition on envirommental and geographical gradientes. Annals of the Missouri Botanical Garden, Cambridge, v. 75, n.1, p. 1-34, 1988.

GIULIETTI, A. M.; FORERO, E. "Workshop" diversidade taxonômica e padrões de distribuição das angiospermas brasileiras. Introdução. Acta Botanica Brasilica, São Paulo, v. 4 n. 1, p. 3-9, 1990.

GIULIETTI, A. M.; RAPINI, A.; ANDRADE, M. J. G.; QUEIROZ, L. P.; SILVA, J. M. C. Plantas raras do Brasil. Belo Horizonte: Conservação Internacional, 2009. 496 p.

HAMMER, Ø.; HARPER, D. A. T.; RYAN, P. D. Past: paleontological statistics software package for education and data analysis. Palaeontologia Electronica, Amherst, v. 4, p. 1-9, 2001.

IBGE - Fundação Instituto Brasileiro de Geografia e Estatística. Mapa da vegetação do Brasil 1: 5.000.000. Rio de Janeiro: IBGE - Diretoria de Geociências, 2004.

IUCN. IUCN red list of threatened species. 2009. Disponível em: $<$ http://www.iucnredlist.org>. Acesso em: 05 abr. 2011.

KÖPPEN, W.; GEIGER, R. Klimate der Erde. Gotha: Verlag Justus Perthes, 1928. Wall-map $150 \mathrm{~cm} \times 200 \mathrm{~cm}$.

KURTZ, B. C.; ARAUJO, D. S. D. Composição florística e estrutura do componente arbóreo de um trecho de Mata Atlântica na Estação Ecológica Estadual do Paraíso, Cachoeiras de Macacu, Rio de Janeiro, Brasil. Rodriguésia, Rio de Janeiro, v. 51, n. 4, p. 69-112, 2000.

KURTZ, B. C.; SÁ, C. F. C.; SILVA, D. O. Fitossociologia do componente arbustivo-arbóreo de Florestas Semidecíduas Costeiras da região de Emerenças, área de proteção ambiental do pau-brasil, Armação dos Búzios, Rio de Janeiro, Brasil. Rodriguésia, Rio de Janeiro, v. 60, n.1, p.129-146, 2009.

LIMA, H. C.; LEWIS, G. P.; BUENO, E. Pau-brasil: uma biografia. In: BUENO, E. (Ed.). Pau-brasil. São Paulo: Axis Mundi. 2002. p. 39-76.

LINO, C. F.; BECHARA, E. Estratégias e instrumentos para conservação, recuperação e desenvolvimento sustentável na Mata Atlântica. Caderno da Reserva da Biosfera da Mata Atlântica: série Políticas Públicas. n. 21. São Paulo: Conselho Nacional da Reserva da Biosfera da Mata Atlântica; Fundação SOS Mata Atlântica, 2002. 83 p.

MANTOVANI, W. Estrutura e dinâmica da Floresta Atlântica na Juréia, Iguape-SP. 1993. 126 f. Tese (Livre-Docência) Universidade de São Paulo, São Paulo, 1993.

MARTINS, F. R. Estrutura de uma floresta mesófila. 2. ed. Campinas: Ed. UNICAMP (Série Teses), 1993. 246 p.

MICHENER, C. D.; SOKAL, R. R. A quantitative approach to a problem of classification. Evolution, New York, v. 11, p. 490-499, 1957.
MMA - MINISTÉRIO DO MEIO AMBIENTE. Instrução normativa n⿳0 06, 23 de setembro de 2008.

MORI, S. A.; BOOM, B. M.; CARVALHO, A. M.; TALMÓN, S. S. Southern Bahian Moist Forest. The New York Botanical Garden, New York, v. 49, n. 2, p. 150-204, 1983.

MUELLER-DOMBOIS, D. E.; ELLENBERG, H. Aims and methods of vegetation ecology. New York: John Wiley \& Sons, 1974. $547 \mathrm{p}$.

PAGANO, S. N.; LEITÃO-FILHO, H. F.; CAVASSAN, O. Variação temporal da composição florística e estrutura fitossociológica de uma floresta mesófila semidecídua - Rio Claro, SP. Revista Brasileira de Biologia, São Paulo, v. 55, n. 2, p. 241-258, 1995.

PAULA, A. Florística e fitossociologia de um trecho de floresta ombrófila densa de terras baixas na Reserva Biológica de Sooeretama, Linhares - ES. 2006. 85 f. Tese (Doutorado em Ecologia e Recursos Naturais) - Universidade Federal de São Carlos, São Carlos. 2006.

PEIXOTO, A. L.; GENTRY, A. H. Diversidade e composição florística da Floresta dos Tabuleiros na Reserva Natural da Vale do Rio Doce (Espírito Santo, Brasil). Revista Brasileira Botânica, São Paulo, n. 13, p. 19-25, 1990.

PETRI, S.; FÚlFARO, V. Geologia do Brasil. São Paulo: Universidade de São Paulo, 1983. 631 p.

PIELOU, E. C. Ecological diversity. New York: John Wiley \& Sons. 1975. 165 p.

POLHILL, R. M.; RAVEN, P. H. (Ed.). Advances in legume systematics. Part 1. Kew: Royal Botanical Gardens, 1981. 1050 p. PRIMACK, R. B.; RODRIGUES, E. Biologia da conservação. Londrina: Ed. UEL, 2001. 327 p.

RICHARDS, P. W. The tropical rain forest: an ecological study. 2 ed. Cambridge, New York, Melbourne: Cambridge University Press, 1981. $450 \mathrm{p}$

ROCHA, Y. T.; SIMABUKURO, E. A. Estratégias de conservação in situ e ex situ do pau-brasil. In: FIGUEIREDO-RIBEIRO, R. C L.; BARBEDO, C. J.; ALVES, E. S.; DOMINGOS, M.; BRAGA, M. R. Pau-brasil: da semente à madeira. São Paulo: Instituto de Botânica/SMA. 2008. p. 101-114.

RODRIGUES, P. J. F. P.; ABREU, R. C. R.; BARCELLOS, E. M. B.; LIMA, H. C.; SCARANO, F. R. Population structure and oneyear dynamics of the endangered tropical tree species Caesalpinia echinata Lam. (Brazilian red-wood): the potential importance of small fragments for conservation. Rodriguésia, Rio de Janeiro, v. 60, n. 1, p.211-220, 2009.

ROLIM, S. G.; IVANAUSKAS, N. M.; RODRIGUES, R. R.; NASCIMENTO, M. T.; GOMES, J. M. L.; FOLLI, D. A.; COUTO, H. T. Z. do. Composição florística do estrato arbóreo da Floresta Estacional Semidecidual na Planície Aluvial do rio Doce, Linhares, ES, Brasil. Acta Botanica Brasilica, São Paulo, v. 20, n. 3, p. 549561, 2006.

SILVA, G. C.; NASCIMENTO, M. T. Fitossociologia de um remanescente de mata sobre tabuleiros no norte do estado do Rio de Janeiro (Mata do Carvão). Revista Brasileira de Botânica, São Paulo, v. 24, n. 1, p. 51-62, 2001.

SILVA-JUNIOR, M. C. Composição florística, estrutura e parâmetros fitossociológicos do cerrado e sua relação com o solo na Estação Florestal de Experimentação de Paraopeba, 
MG. 1984. 130 f. Dissertação (Mestrado em Ciência Florestal) Universidade Federal de Viçosa, Viçosa. 1984.

SOS MATA ATLÂNTICA; INPE (Instituto Nacional de Pesquisas Espaciais). Atlas da evolução dos remanescentes florestais e ecossistemas associados no domínio da Floresta Atlântica no período de 2008-2010. São Paulo: Fundação SOS Mata Atlântica/ INPE/ISA. 2011. 122 p.

TABARELLI, M.; MANTOVANI, W. Colonização de clareiras naturais na Floresta Atlântica no sudeste do Brasil. Revista Brasileira de Botânica, São Paulo, v. 20, n. 1, p. 57-66, 1997.
TABARELli, M.; MANTOVANI, W.; PERES, C. A. Effects of habitat fragmentation on plant guild structure in the montane Atlantic forest of southeastern Brazil. Biological Conservation, Boston, v. 91, p. 119-127, 1999.

THOMAZ, L. D. Florística e fitossociologia da Floresta Atlântica na Estação Biológica de Santa Lúcia, Santa Teresa/ES. 1996. 322 f. Tese (Doutorado em Ciências Biológicas) - Universidade Estadual Paulista, Rio Claro. 1996. 